\title{
Study of Current Femto-Satellite Approches and Services
}

\author{
Nizar Tahri,Chafaa Hamrouni, Adel M.Alimi \\ REGIM-Lab: Research Groups on Intelligent Machines \\ Department of Electrical Engineering, National Engineering School of Sfax (ENIS) \\ BP1173, Sfax 3038, Tunisia \\ nizar.isi@1aposte.net, \{chafaa.hamrouni,adel.alimi@ieee.org\}
}

\begin{abstract}
The success of space technology evolves according to the technological progression in terms of density of CM OS integration (Complementary on - Silicon Metal) and MEMS (Micro-Electro-Mechanical System) [4]. The need of spatia $l$ services has been a significant g rowth due to several fac tors such as population increases, teleco mmunication applications, climate changes, earth control and observation military goals, and so on. To cover this, s patial vehicle generations, specific calculators and Femto-cell systems have been developed. More recently, Ultra Small Satellites ( USS) have been proposed and d ifferent approaches, concerning developing of these kind of spatial systems, have been pr esented in lit erature. This miniature satell ite is capable to fly in the space and to provide different services such as imagery, measures and communications [4, 9, 10]. This paper deals with the study of two different USS Femto-sat ellite architectures that exist in literature in order to propose a future architecture that can provide an optimization of power supply consumption and ameliorate service communication quality.
\end{abstract}

\section{Keywords: Femtosatellite, Communication, Spacecraft}

\section{INTRODUCTION}

In the last few decades, a ne w generation of space mission architecture design is em erging in USS. It wi 11 collectively perform missions; both earth-orbiting and intersatellite communication, in a dist ributed fashion. Solutions have been already proposed for optimization of complex distributed space mission architectures. However, to support such architectures, a novel approach, with a high volume production of Femto-Satellite less than $100 \mathrm{~g}$ satellites-on-achip or satellite on board at low cost, is required.

In this paper we present the migration for the USS and we detail a probe of two FemtoSatellite approaches. The first one is named Fem to-Satellite-On-Chip, the second one is named Femto-Satellite-On-Board or Femto-Satellit e based on Com mercial-Of-The-Shelf (COTS). Moreover, a comparison study of these approaches is done to show the difference between them and then to propose a future architecture.

The paper is structured as following. T he next section expands migration towards the USS and especially toward the Femto-Satellite. Section 2 presents an evaluation of ten year-research on USS. Section 3 expands migration towards Femto-Sat-COTS. Section 4 sho ws comparison between PCBSat and Wiki-Sat from two points of view. Section 5 lists the Fem toSatellite theme researches. Section 6 is de voted to discuss the two architectures comparison results. Last but not least, the paper concludes with roadmap of future researches required to realize a specific FemtoSatellite from Tunisia with COTS approach.

\section{Migration tOWARD THE Ultra-SMALL- SATELLITE GENERATION}

Classification of satellites frequently depends on its masses. Actually, we talk about satellites which are inferior to $1 \mathrm{~kg}$ and sometimes to some grams, as shown on table 1 . PicoSat is, eventually, lar ger than Fem toSatellite, AttoSatellite and ZeptoSatellite [11]. This passage i s justified with the technol ogical evolution i $n$ terms of integration density. In $\mathrm{t}$ he last decades, the worl $\mathrm{d}$ of technology manifested mixing between the conce ption of micro-electromechanic MEMS approach and the conception of electronic CMOS approach [13], which allows the development of ca ptors, processors and systems that are completed on a miniature surface even granular. These miniature systems offer the advantage of reducing the cost of production as well as the cost by prototype [11].

Table 1: Ultra-Small Satellite

\begin{tabular}{|c|c|c|}
\hline & Weight & Price \\
\hline PicoSatellite & $\sim 1 \mathrm{~kg}$ & $\sim 10000 \$$ \\
\hline FemtoSatellite & $\sim 0.1 \mathrm{Kg}$ & $\sim 100 \$$ \\
\hline AttoSatellite & $\tilde{0} 0.01 \mathrm{Kg}$ & Few \$ \\
\hline ZeptoSatellite & $0.001 \mathrm{Kg}$ & Few \$ \\
\hline
\end{tabular}

Researches on Pico-Sat are very advanced, but only some of these satellites are functioning. Many of Pico-Sat is missed after their launc hing and alm ost 30\% s hows good results [16]. This result, as it is shown on figure 1, represents the major problem of PicoSat when c onnecting the number of satellites non-func tioning with the cost of development. 


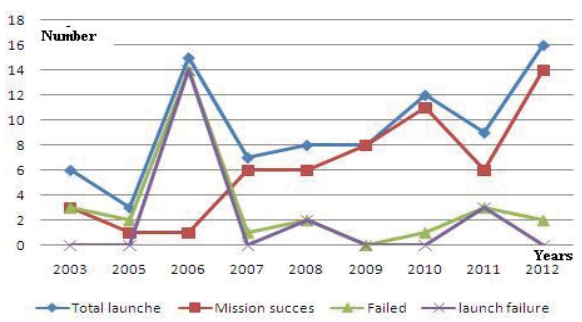

Fig.1: Histogram of cube satellite in the world [16]

Requirements to m inimize development cost and time push researches towards satellite generations. In order to offer more chance to the entire world to design their own satellites responding to particular requirem ents, these generations are developed to be cheaper, more rapid to be on service, simpler to function and with a commercializ ed technology [1]. Figure 2 displays a comparison according to five parameters including PicoSats and FemtoSats. These parameters offer the adva ntage of $m$ igration from the PicoSat generation to the Femto Sat. We can note that this position of FemtoSat focus on its architecture and its power in terms of services and lifetime.

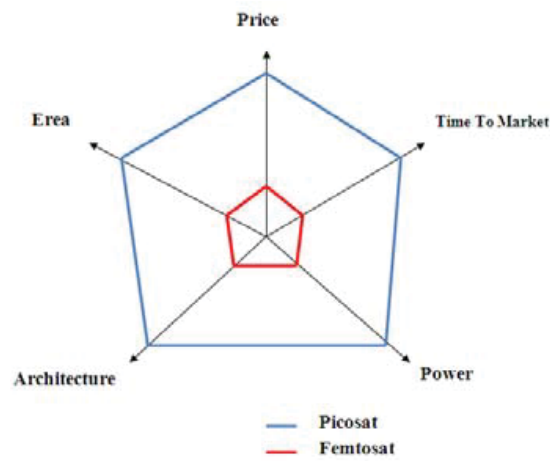

Fig. 2: Comparison between PicoSats and FemtoSats

\section{EVALUATION OF TEN YE AR-RESEARCH OF USS}

Since the birth of integration technol ogy, with mixing of electric and mechanic systems known as MEMS approach, engineers and researchers of technology space opted a conceive; a satellite according to the miniaturization norms, for instance N-Prize [6]. This perspective began with conception of em bedded systems that include all classica 1 satellite subsystems. Meanwhile, the miniaturization has confronted an obstacle which ha s changed, until now, the axes of the research; it is the insufficiency of energy [1]. In the beginning, researchers migrated toward a satellite on chip by integrating solar energy as a hybrid source. Winsat and Smart Dusts are examples that show this philosophy in Silicone and on chip smaller than fraction of centimeters as shown on figure 3 [4].

The use of Fe mto solar cells cause d problems of integration since the two appr oaches, CMOS and Solar Cells, aren't compatible [4]. But many studies have show $n$ the feasibility without really having a com plete launched system.
149

\begin{tabular}{|c|c|c|}
\hline & Picture & Reference \\
\hline PCBSat & 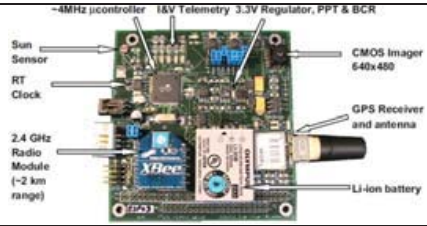 & [11] \\
\hline WikiSat & & [6] \\
\hline
\end{tabular}

Fig.3: Two types of FemtoSatellite

This Femto-satellite evolution equally with the technological development of capturers and commercialized microscopic actuators c onception, raised questions on the possibility of desi gning granular Femto-satellites with discrete commercialized componen ts. Indeed, in 2009, D. Barnhart published the firs t FemtoSatellite on board [11]. He named this satellite PCBSat accordi ng to the didactic norms inherited of his EsaySat ancestor of the Picosat family. This satellite has been viewed as a map on board of some centimeters which integrates the based subsystems of a classic satellite as shown on table 2 .

In 2011, J. Tristancho published t he first WikiSat generation fruit of a spatial-aerospace competition called NPrize [6]. This competition has presented pa rticular specifications for the Fem toSat future that are summarized by size inferior to $20 \mathrm{gr}$, use of COTS components and low conception cost. WikiSat is, actually, referenced as a landmark not only to study the exploration of Fem toSat in certain applications but also to testify certain updated components.

\section{USS-ON CHIP MIGRA TION TOWARD FEMTOSATELLITE-ON-COST}

In [12], D. Barnhart studied FemtoSatellites. He started his career with Wisnet, a result which is published in 2007 and shown in table2. This satellite on chip is sized to navigate in low orbits after capturing earthly images. It was equippe $d$ with Femto-solar cells planned to produce a low power less than $\mathrm{mW}$ [6]. Meanwhile, $\mathrm{m}$ iniaturization minimized consumed energy, but the s ources remain insufficient and limited. The hybrid solution has been studied as a classic solution, however, many constrains has been established. They, also, limited the commer cialization of this satellite generation. Among these constrains, we site the expe nsive cost of not only the CS so lar cell manufacturing but all the embedded Femto-cells, since we need two different technologies such as CMOS for the electronic com ponents, as well as the CS (table 2) [11]. The cost remained hugely high compared to many solutions which were more popular and less complex. Satellites on miniature board are proposed as a concurrent solution. Moreover, it is until 2009 that D. 
Bernhat has published his second FemtoSatellite generation designed on board [11].

Table 2: Historic of 10 years FemtoSat generation

\begin{tabular}{|c|c|c|c|c|}
\hline & Author & Sat-name & Year & Reference \\
\hline \multirow{2}{*}{$\begin{array}{l}\text { Femto } \\
\text { Sat-On } \\
\text { Ship } \\
\end{array}$} & A. Brett et al & Dust Smart & 2002 & [14] \\
\hline & D. Barnhart et al & WISNET & 2007 & {$[12]$} \\
\hline \multirow{2}{*}{$\begin{array}{l}\text { FemtoSat- } \\
\text { On Board }\end{array}$} & D. Barnhart & PCBsat & 2009 & [11] \\
\hline & J. Tristancho et al & WIKISat & 2011 & [6] \\
\hline
\end{tabular}

\section{COMPARISON BETWEEN TWO USS ON BROAD: PCBSAT AND WIKISAT}

Comparison between two C OST FemtoSatellites aims, as an objective, at fam iliarizing with the spati al satellite technology as well as finding a c oncrete amelioration or e xploration based on architecture $\mathrm{s}$. Eventually, levels of comparison are classified from general to specific terms based on both D. Bernhart and J. Tina works $[6,8,9]$.

\section{1) High level comparison: functional, structural}

Satellite in general, and FemtoSatellite in particular, is composed of six large s ubsystems that can also be subdivided elementarily. These subsystems assure the navigation, the communication, the management, and the captures by using a de dicated structure and one or more sources of energy. Often, we find other classifications of subsystems such as the navigation which is responsible for the control and the determ ination of the attitude as well as the position.

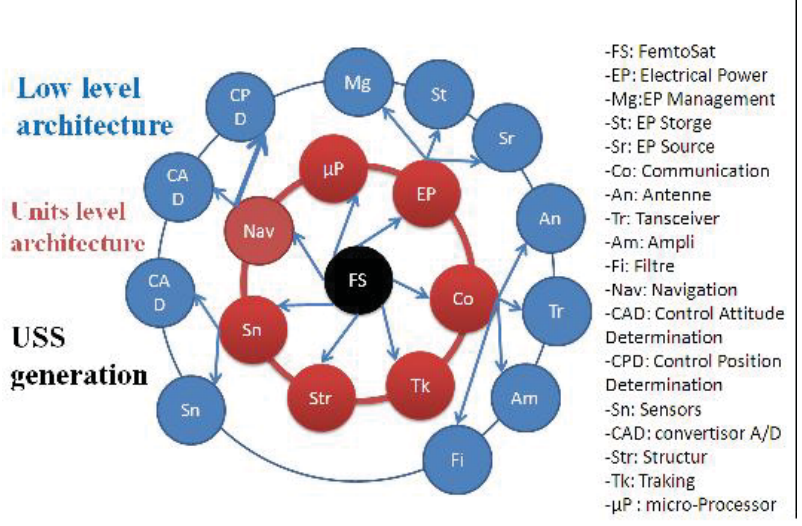

Fig.4: Basic architecture of FemtoSatellite

In this section, we focus on com paring, without technical specifications, two FemtoSatellites as shown on figure 4. In fact, PCBSat is advantaged relatively to WikiSat by the inte gration of 7 solar cells, a G PS and a Ra dio Frequency module ZegBee [3]. These modules, respectively, offer more energetic autonomy and $\mathrm{m}$ ore flexibility in communication, despite the fact that this WikiSat is advantaged by miniaturization. However, as we have said, we haven't found other criteria of general order to compare, for instance; the applications, the services etc... In the section 5, we will study, in details, all the param eters available in the two prototypes.

\section{2) Low level comparison: subsystems}

This part highlights the different architectural parameters of two FemtoSatellites. Table 3 summarizes this comparison that displays the possibility of miniaturizing the satellite. Thereby, this trend encapsulated multitasking and multi-discipline systems that still suffer from energetic limitation which influences the service quality and the lifetime of satellite $[6,11]$.

Table 3: Specification of PCBSat and WikiSat

\begin{tabular}{|c|c|c|c|}
\hline \multicolumn{2}{|c|}{ Subsystems } & PCBSAT & WIKISAT \\
\hline \multicolumn{2}{|c|}{$\begin{array}{l}\text { Masse/system mass } \\
\text { (gr) }\end{array}$} & 70 & 19,7 \\
\hline \multicolumn{2}{|c|}{ dimensions } & 9x9x1 cm (PC104) & $30 \times 25 \times 7 \mathrm{~mm}$ \\
\hline \multicolumn{2}{|c|}{ Cost per prototype $(\$)$} & 300 & 100 \\
\hline \multicolumn{2}{|c|}{ Payload } & $\begin{array}{l}\text { 640x480 } \\
\text { imager }\end{array}$ & $\begin{array}{l}\text { 1280x } 1024 \\
\text { CMOS imager }\end{array}$ \\
\hline \multirow{3}{*}{$\begin{array}{l}\text { Electrical } \\
\text { power } \\
\text { subsystem }\end{array}$} & $\begin{array}{l}\text { Solar } \\
\text { cells }\end{array}$ & 6 Solar cell $689 \mathrm{~mW}$ & No \\
\hline & Battery & $\begin{array}{l}645 \quad \mathrm{~mA} \quad \text { Li-ion } \\
\text { battery }\end{array}$ & $\begin{array}{l}3 \mathrm{v} / 610 \mathrm{mAh} \mathrm{Li-} \\
\text { ion battery }\end{array}$ \\
\hline & $\begin{array}{l}\text { Regulator } \\
\text { and } \\
\text { controller }\end{array}$ & $\begin{array}{l}-3,3 \text { v regul ated } \\
\text { system bus } \\
\text { - Peak power tracking } \\
\text { Battery charge } \\
\text { regulation } \\
\text {-6-chanel telemetry }\end{array}$ & -- \\
\hline \multicolumn{2}{|c|}{$\begin{array}{ll}\text { Data } & \text { Handling } \\
\text { Subsystem } & \end{array}$} & $\begin{array}{l}\text { Mega } 128 \mathrm{~L} \\
\text { microcontroller } \\
\begin{array}{l}3.6864 \text { Mhz system } \\
\text { clock }\end{array}\end{array}$ & $\begin{array}{l}\text { ATmega328P } \\
\text { MCU } \\
8 \mathrm{MHz} \\
(\mathrm{v}<3,3)\end{array}$ \\
\hline \multicolumn{2}{|c|}{$\begin{array}{l}\text { Communication } \\
\text { Subsystem }\end{array}$} & $\begin{array}{l}\text { 2,4 GHz } 60 \mathrm{~mW} \text { RF } \\
\text { ZigBee protocol } \\
\text { Signal strength } \\
\text { telemetry }\end{array}$ & $\begin{array}{ll}2,4 & \mathrm{GHz} \\
\text { Wireless radio }\end{array}$ \\
\hline \multirow{3}{*}{\multicolumn{2}{|c|}{$\begin{array}{l}\text { Attitude and Orbit } \\
\text { Control/Determination } \\
\text { Subsystem }\end{array}$}} & \multirow{3}{*}{$\begin{array}{l}\text { Passive aerodynamic } \\
\text { Tow sun sensors } \\
\text { GPS receiver }\end{array}$} & $\begin{array}{l}\text { ADS: } 4 \text { optic } \\
\text { sensors }\end{array}$ \\
\hline & & & $\begin{array}{l}\text { PDS : 3D } \\
\text { accelerometer } \\
\text { 3D } \\
\text { gyrometer }\end{array}$ \\
\hline & & & $\begin{array}{l}\mathrm{ACS}: \\
\text { magnetorquer }\end{array}$ \\
\hline \multicolumn{2}{|c|}{$\begin{array}{ll}\text { Termal } & \text { Control } \\
\text { Subsystem } & \end{array}$} & $\begin{array}{l}\text { Solar cell and battery } \\
\text { Temperature } \\
\text { monitors }\end{array}$ & No planned \\
\hline \multicolumn{2}{|c|}{ Structural Subsystem } & TBD & Fiberglass \\
\hline \multicolumn{2}{|c|}{ Propultion } & None planned & None planned \\
\hline
\end{tabular}

The major specific architectural differences are situated in power and communication subsystems, particularly the a ntenna module. In fact, this power modification not only increases the weight but als o integrates the additional components for control, regulation and distribution of power [11]. Indeed, a multi-source power system has, often, a cont roller that $\mathrm{m}$ onitors the charge level, a distribute $r$ that dire cts the flow of current and a 
regulator that adapts the tension as well as rewarding the lack of energy from secondary source. These sub-modules occupy more space and cons ume more energy, the fact that influences the masse and the lifetime. Similarly, the integration of a specific antenna raises the question about the supplement components: amplifier, filter, converter a nd the transceiver. These components should be targeted after guaranteeing better operation, taking into c onsideration the size and the weight. For this reason, the actual spacecraft researches still work on the modeling, the conception and the integration of secondary re newable energy sources and the antenna, chip for high gain with low power.

\section{FIELDS OF ACTUAL RESEARCHES ON FEMTOSATS ON BOARD}

The previous comparison showed that the gene ral architecture kept the same specifications except some in the sensitive modules. Power is am ong the extrem ely sensitive modules. In fact, it influe nces other modules like communication and captures.

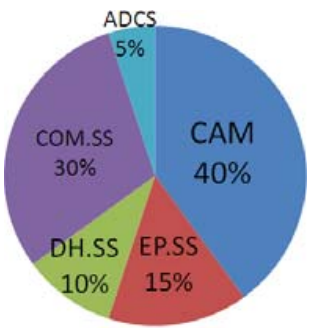

Fig.5 (a) :

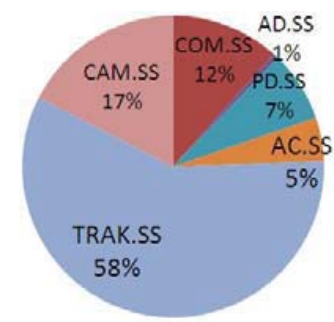

(b)

\section{(a): Power distribution PCBSat}

(b) :Power distribution WikiSat

Power distribution, displayed on figure 5 (part a and b), presents all greedy subsystems in term $\mathrm{s}$ of power. Communication and im aging sensors are the $\mathrm{m}$ ost demanding power modules, where the necessity of searching other more optimist antennas and cam eras exists. Similarly, WikiSat has three critical modules; communication, sensor imaging and tracking. All the modules directly influence the lifetime in space which ha $\mathrm{s}$ been already limited by the resource insufficiency. Actually, researches are around some minutes [3]. These limitations are, nowadays, the large perspectives of research. Works are distributed between the updates of commercialized components, the study of certain modules such as co mmunication and the exploration of FemtoSat services.

\section{1) Modeling of subsystems}

Modeling, first of all, builds a mathematic model of the phenomena, which is called the digital modeling. Then, this model will be transformed in an observable system where we ca $n$ change the parameters [7]. There by, these digital and analogical modelings are treated in several works such as:
- In 2011, Chang-Chan de signed the power system of USS by specifying the solar cells and the battery [11]. In fact, he calculated the provid ed solar power, masses, and the lifetime of the satellite functioning by his battery.

- In 2012, Sunday studied and analyzed the architecture of the new adaptive miniature satellite generation [2]. $\mathrm{He}$ oriented the power efforts of spatial syste $\mathrm{m}$ toward the conception of system on boa rd with com mercialized modules keeping a se rvice quality and a masse/power compromise. He designed the weight, the used power and the lifetime.

These modelings, later on, facilitate the conception and even the research of optimist components. However, they are not followed by concrete realizations, the fact that raises the question of their feasibility. Despite this, certain works, that we will detail la ter on, have responded at this question as well as finishing the prototypes.

\section{2) Study and conception of FemtoSatellite subsystems: Antenna}

Power and $\mathrm{c}$ ommunication are the $\mathrm{m}$ ost delicate modules since they allow re assuring the link between the satellite and its world during life stage in space. Indeed, this link has several levels regarding the type of communication. For instance, Iverson Bell studied this problem in a way to profit the spatial waves i $\mathrm{n}$ order to get an electromagnetic charge [4].

Besides, the s pace has ever attached researchers as a renewable power source. This power is found in the form of waves, luminous photos and particula $r$ charged gaseous. Exploration of such sources requires a powerful technology and a modeling knowledge in order to design sensor costs. Solar cells are among the studied sensors, but their yields aren't, until now, effective t o $100 \%$. Harvested current is trying low a point that the cells' surface should be trying large so that we can get an autonomic power. Chang-Chun estimated this power by $0.025 \mathrm{Kg} / \mathrm{W}$ and with a yield of $15 \%$ [7]. These res ults don't support the Fem toSat development, in a way, to insist guarding the CS, without forgetting that explorations of such cells, opposite to the sun, aren't positioned and this time aren't also to exceed 20 minutes at 2 hours cycle per orbital rotation.

The insufficiencies of Fem toSatellite power impose the optimist communication use, str ictly to guarantee that the satellite won't be lost in space or won't be incapable of assuring such a service. Oft en, we find 3 communication types:

Extra-Communication: with an ea rthly control chamber that commands and controls the FemtoSat and the sensor measurements.

- Intra-Communication: it's comm unication into FemtoSatellites with constellation. This communication assures sharing task or data since FemtoSat is in capable of assuring such a service lonely. This incurability is due to its coverage and its limited power. 
- Inter-Communication: it's the communication with grand station generally situated at high orbits.

These three modules of communication impose the use of a high gain antenna with low power consumption. In 2011, Enric.F proposed a specific antenna for WikiSat [8] regarding the followi ng constrains:

- Weights : 7,6 gr

- $\quad$ Frequency band : UHF 2,4 à 2,5 GHz

- Resistance : 50 ohms

- Coverage : --

- $\quad$ Power: --

- Gain : $16 \mathrm{~dB}$

This antenna displayed in table. 4 is testified by altitudes inferior to $50 \mathrm{Km}$ after launching. Tests showed a stability of operation. But t his operation wasn't final because WikiSat didn't reach orbits of $200 \mathrm{Km}$ in total functioning.

Table 4: Tow FemtoSat Antenna

\begin{tabular}{|l|c|c|}
\hline & WIKI-Sat antenna & FEMTO-Sat linear antenna \\
\hline Picture & & \\
& & \\
\hline Authors & E. Fernandez-Murcia & C.Hamrouni et al \\
\hline Ref & {$[8]$} & {$[5]$} \\
\hline
\end{tabular}

C.Hamrouni et E, Gill studied and desi gned antennas (table.4) that respond to FemtoSatellite re quirement except that the latter isn't testified on a real FemtoSat. The antenna conception isn't to be the first between communication module conceptions. Indeed, noise management and synchronization of c ommunication are also of hi gh complicity order [1]. These reasons are actually behind the delay of functional launching of FemtoSat. However, in this year 2013, it's proved that the Europea n Community will launch its Swarm, composed of three FemtoSatellites. It's a real test of such a kind of satellite.

\section{3) Update of COT Subsystems: Imagery sensor}

The basic motivation of FemtoSatellite on board conception is to reduce the production cost and use the COTS components. The objective rem ains the focus of many studies of certain researchers that opt $t o$ find an adequate material configuration with $\mathrm{m}$ ission, power and weight constrains. Indeed, in 2011, Luis Izquerdo published a new study of Fem toSatellite generation with high resolution- observation -earth syste m (OES) by 14 Mpix with an optimist power [9]. This study isn't standardized since the OES technology evaluates rapidly. Moreover, these sensors remain insufficient because the FemtoSatellite specifications find that integrating high quality sensor wi th low power c onsumption and more miniaturizing. This energy/quality paradox is generally difficult to manage. The case of solar cell integration is the classic exam ple of this relation. In fact, we look for getting autonom ous satellites with renewable power sources but the CS yield rem ains insufficient if we use a small area/wide cell. Besides, the use of several CS provokes a large masse and temperature that can disrupt the regular operation. For this reason, PCBSAT uses many thermal sensors [11] while it is not th e case for WikiSat.

Update of sensors provokes the architecture change. Amelioration of i ntegration and MEMS technology evolution can product future FemtoSats on boa rd that are more miniature and effective as well as with sim pler architecture to $\mathrm{m}$ anipulate. This trend cannot be reached without getting s pecific module conception since the real optimization is, by definition, linked to a specific approach.

\section{4) Feasibility application study}

Actual space technology becomes accessible for all the world, the fact that proves $m$ any countries as Spai $n$ which studied WIKISAT in 2011 and Tunisia which studied l'EREPSAT1 in 2009 [ 15]. This orientation offers many countries, societies and even in dividuals to build their personal satellites.

Chile makes an example of constellation study with FemtoSatellite for controlling the climatic change from the space in order to guess the security [3]. The countries that are situated on the cyclone trajectory or that ha ve nuclear constructions are the focus of observers in order $t o$ reform dynamic data base on climate, atmospheric temperature and gaze concentration.

The FemtoSatelitte is the $\mathrm{f}$ uture solution if it guards the following principles [10]:

- $\quad$ Simpler and more functional : KISS (keep it Simple and Safe) [6]

- Low and reliable costs

- Miniature autonomous power

Feasibility study gives the opportunity to valorize and to prove the Fe mtoSatellite efficacy in order to be the first generation of personal sat ellite. Indeed, low cost by prototype and launc hing encourages countries and researchers to study and to design prot otypes until their use in the following services:

- Observation system

- Help decision system

- $\quad$ Security and military control system

- Didactic research system

- Commercial imagery system

These systems can be effective in securing populations, the atmosphere security and the eart $\mathrm{h}$ monitoring. In fact, these are among the advantages of digital space technology. Consequently, the picture of nowadays is viewed not only as a color collection but also as a source of metrological data. 


\section{DISCUSSION}

We notice that the two FemtoSatellites WIKISat and PCBSat share the same principal of COTS conception except the fact that they differ in the use of some specific modules. The two prototypes focused on the masse and the form guarding a basic $\mathrm{m}$ odular architecture. PCBSat is purely commercialized and presents more advantages by the use of solar power. However, WIKISat uses a specific antenna limiting itself to a unique source of power in the form of a battery. The advant age of WIKISat in term of the integration of a specific antenna gives much more flexibility and power in communication and of fers a more adaptable structure. E. Fernandez and C. Hamrouni worked on this module in order to product an antenna generation which is more miniature and adequate instead of LEO communication $[5,8]$. Nevertheless, there is no unique conception, the question of communication performance remains raised since it is the most critical ele ment in the FemtoSatellite functionality that has already suffered from power limitation and $\mathrm{m}$ asse. It also should optimize the consumption, the management and the com munication synchronization. Until now, the test of a FemtoSatellite constellation hasn't already been validated and problems of synchronization between FemtoSat with same constellation haven't already been tested too.

The first real event that will test this satellite is expected in the European competition Swarm in March 2013 [10]. P.Sundaram oorth, studied the Fe mtoSat ability, made this mission the fact that valorizes all optimization on power and communication. Indeed, the triple functionalitypower-communication relationship remains a restraint to study for coming generations. The antenna is, consequently, the element-engine in this bilon. It remains a motivating of research field for a Fem toSat generation that looks for maximizing the spatial lifetime by the optimization of power consumption.

\section{CONCLUSIONS}

In this peppers we have presented a comparison between two approaches of USS FemtoSatellites. We have showing that engineering space is evolving rapidly in parallel with the evolution of mixed integration technology CMOS / MEMS. This Migration from one generation to another satellite has reache $d$ the stage of satellite-on- chip. These types of miniature satellites have specific missions in low orbits. Among others, the miniaturization of this system is coupled with a multi-energy deficiency which limits the lifetime of such a satellite. Communication also suffers from several constraints related to this low energy but also to the nature of the space which is noisy and loaded with thermal and magnetic fields that can affect the operation or the quality of FemtoSatelitte services. During this last decade, the research has detailed architecture and has modeled some subsystems without actually launching a prototype FemtoSat in a real application. This lack of real parameters allows the opportunity for researchers $t$ o build m ultiple architectures and explore some specific s ubsystems to optimize energy and mass keeping a lim ited quality service. The antenna presents one of the most principal elements that can provide a real contribution in the future generation of FemtoSatellite on Board. Further works will be done on the novel architecture conception ba sed on a specifi c patch antenna mixed to a communication module.

\section{REFERENCES}

[1] P.P. Sundaramoorthy , E.Gill , C.J.M.Verhoeven, "Enhancing ground communication of distributed spa ce systems",Acta Astronautica Volume 84, pp 15-23, March-April 2013.

[2] I. Bell and B. Ilchrist, "Investigatio ng the use of Miniaturization electrodynamic tethers to enhace the capabilites of femtosatellite and other ultra-small-satellite", $26^{\text {th }}$ annual AIAA/USU conference on Small satellite, LOGAN Utah USA, 13-16/08/2012,

[3] Sunday C. Ekpo, "A Sy stem Engineering Consideration for FutureGenerations Small Satellites Design", Satellite Telecommunications (ESTEL), 2012 I EEE First A ESS European Confe rence, Centro Congressi Roma Eventi Fontana di Trevi Rome, Italy, pp: 1 - 6, 02 Oct - 05 Oct 2012 .

[4] A. Becerra all, "Feasibility Study of using a $\mathrm{S}$ mall Satellite Constellation to Forecast, Monitor and Mitigate Natural and Manmade Disasters in Chile and Sim ilar Developing countries", 26 th annual AIAA/USU conference on Small satellite 13-16/08/2012, LOGAN Utah USA.

[5] Ch. Hamrouni, A. Abraham, and A. M. Alimi, "Both Sides Linked Antenna Array for Ultra S mall Satellite Communication Subsystem", 2012 International Conference on I nnovation, Management and Technology Research (ICIMTR2012), Malacca, Malaysia :21-22 May, 2012

[6] J. Tristancho and J. Gutierrez-Cabello, "A Probe of Concept for FEMTO-SATELLITES based on Commercial-Of-The-Shelf", Digital Avionics Systems Conference (DASC), 2011 IEEE/AIAA 30th Seattle, Washington, USA , pp: 8A2-1 - 8A2-9, 16-20 October 2011

[7] Ch. Chen, "The Satellite Optimization Design Using Normal Cloud Model Method", 2011 Internati onal Conference on Network Computing and Information Security

[8] E. Fernandez-Murcia, Luis Izquierdo, et Joshua Tristancho, "A Synthetic Aperture Antenna A for FEMTO-SATELLITES Based On Commercial-Of-The-Shelf', Digital Avionics System s Conference (DASC), 2011 IEEE/AIAA 30 ${ }^{\text {th }}$, Seattle, Washington, USA, pp: 8A31 - 8A3-12., 16-20 October 2011 .

[9] L. Izquierdo, J. Tristancho, "Next Generation of Sensors for FEMTOSATELLITES Based On Co mmercial-Of-The-Shelf", Digital Avionics Systems Conference (DA SC), 2011 IEEE/AIAA 30 ${ }^{\text {th }}$, pp: 8A4-1 - 8A4-7, Seattle Washington USA, 16-20 October 2011.

[10] P.P. Sundaramoorthy, E. Gill and C.J.M. Verhoeven, "Systematic Identification of Applicati ons for A Cluster of FEMTOSATELLITES", 61st International Astronautical Congress, Prague,27/09/ 2010

[11] D.Barnhart, "Alow-Cost FEMTO-SATELliTES To Enable Distributed Space Missions" , Acta Astronautica 64 Science direct, 9/03/2009

[12] D. Barnhart, T. Vladimirova, and Martin N. Sweeting, "System-OnA-Chip Design of Self-Powered Wi reless Sensor Nodes for Hostile Environments", Aerospace Conference IEEE, Big Sky Montana, pp: $1-12$, 3-10- 2007

[13] D. Barhart and T. Vladimirova, "Design of Self Powred Wirless System On Chip Sensor Nodes for Hostile Environment", Aerospace Conference IEEE, Seattle Washington, pp: $824-827,18-21$ May 2008

[14] A. Brett, D. Michaeland all, "An Autonomous $16 \mathrm{~mm} 3$ SolarPowered Node for Distributed Wireless Sensor Networks", ICSENS. Hyatt Orlando, Florida, USA, pp : 1510 - 1515 vol.2, 12-14 June 2002 .

[15] B.Neji, C.Hamrouni, and A.M Alim i, "EREPSat-1 Scientific Pico Satellite Development", Systems conference, $4^{\text {th }}$ Annual IEEE, San Diago California, pp: 255-260, 5-8 april 2010.

[16] Darren D. Gar ber, Ph.D.' The CubeSat Challenge: A Review of CubeSat Dependencies and Require ments for S pace Tracking Systems" . 19 July 2012 